
\title{
OPEN Toxic fluoride gas emissions from lithium-ion battery fires
}

Received: 11 April 2017

Accepted: 28 July 2017

Published online: 30 August 2017

\author{
Fredrik Larsson ${ }^{1,2}{ }^{2}$ Petra Andersson ${ }^{2}$, Per Blomqvist ${ }^{2}$ \& Bengt-Erik Mellander ${ }^{1}$
}

Lithium-ion battery fires generate intense heat and considerable amounts of gas and smoke. Although the emission of toxic gases can be a larger threat than the heat, the knowledge of such emissions is limited. This paper presents quantitative measurements of heat release and fluoride gas emissions during battery fires for seven different types of commercial lithium-ion batteries. The results have been validated using two independent measurement techniques and show that large amounts of hydrogen fluoride (HF) may be generated, ranging between 20 and $200 \mathrm{mg} / \mathrm{Wh}$ of nominal battery energy capacity. In addition, $15-22 \mathrm{mg} / \mathrm{Wh}$ of another potentially toxic gas, phosphoryl fluoride $\left(\mathrm{POF}_{3}\right)$, was measured in some of the fire tests. Gas emissions when using water mist as extinguishing agent were also investigated. Fluoride gas emission can pose a serious toxic threat and the results are crucial findings for risk assessment and management, especially for large Li-ion battery packs.

Lithium-ion batteries are a technical and a commercial success enabling a number of applications from cellular phones to electric vehicles and large scale electrical energy storage plants. The occasional occurrences of battery fires have, however, caused some concern especially regarding the risk for spontaneous fires and the intense heat generated by such fires ${ }^{1-5}$. While the fire itself and the heat it generates may be a serious threat in many situations, the risks associated with gas and smoke emissions from malfunctioning lithium-ion batteries may in some circumstances be a larger threat, especially in confined environments where people are present, such as in an aircraft, a submarine, a mine shaft, a spacecraft or in a home equipped with a battery energy storage system. The gas emissions has however only been studied to a very limited extent.

An irreversible thermal event in a lithium-ion battery can be initiated in several ways, by spontaneous internal or external short-circuit, overcharging, external heating or fire, mechanical abuse etc. This may result in a thermal runaway caused by the exothermal reactions in the battery ${ }^{6-10}$, eventually resulting in a fire and/or explosion. The consequences of such an event in a large Li-ion battery pack can be severe due to the risk for failure propagation ${ }^{11-13}$. The electrolyte in a lithium-ion battery is flammable and generally contains lithium hexafluorophosphate $\left(\mathrm{LiPF}_{6}\right)$ or other Li-salts containing fluorine. In the event of overheating the electrolyte will evaporate and eventually be vented out from the battery cells. The gases may or may not be ignited immediately. In case the emitted gas is not immediately ignited the risk for a gas explosion at a later stage may be imminent. $\mathrm{Li}$-ion batteries release a various number of toxic substances ${ }^{14-16}$ as well as e.g. $\mathrm{CO}$ (an asphyxiant gas) and $\mathrm{CO}_{2}$ (induces anoxia) during heating and fire. At elevated temperature the fluorine content of the electrolyte and, to some extent, other parts of the battery such as the polyvinylidene fluoride (PVdF) binder in the electrodes, may form gases such as hydrogen fluoride $\mathrm{HF}$, phosphorus pentafluoride $\left(\mathrm{PF}_{5}\right)$ and phosphoryl fluoride $\left(\mathrm{POF}_{3}\right)$. Compounds containing fluorine can also be present as e.g. flame retardants in electrolyte and/or separator ${ }^{17}$, in additives and in the electrode materials, e.g. fluorophosphates ${ }^{18,19}$, adding additional sources of fluorine.

The decomposition of $\mathrm{LiPF}_{6}$ is promoted by the presence of water/humidity according to the following reactions ${ }^{20,21}$;

$$
\begin{gathered}
\mathrm{LiPF}_{6} \rightarrow \mathrm{LiF}+\mathrm{PF}_{5} \\
\mathrm{PF}_{5}+\mathrm{H}_{2} \mathrm{O} \rightarrow \mathrm{POF}_{3}+2 \mathrm{HF} \\
\mathrm{LiPF}_{6}+\mathrm{H}_{2} \mathrm{O} \rightarrow \mathrm{LiF}+\mathrm{POF}_{3}+2 \mathrm{HF}
\end{gathered}
$$

${ }^{1}$ Department of Physics, Chalmers University of Technology, Kemivagen 9, SE-41296, Gothenburg, Sweden. ${ }^{2}$ Safety and Transport, RISE Research Institutes of Sweden, Brinellgatan 4, SE-50115, Boras, Sweden. Correspondence and requests for materials should be addressed to F.L. (email: vegan@chalmers.se) 


\begin{tabular}{|l|l|l|l|l|l|}
\hline Battery & $\begin{array}{l}\text { Numbers of } \\
\text { batteries per test }\end{array}$ & Type & $\begin{array}{l}\text { Nominal capacity } \\
\text { per battery }(\mathrm{Ah})\end{array}$ & $\begin{array}{l}\text { Nominal voltage } \\
\text { per battery (V) }\end{array}$ & Cell packaging \\
\hline A & $5-10$ & $\mathrm{LCO}\left(\mathrm{LiCoO}_{2}\right)$ & 6.8 & 3.75 & $\begin{array}{l}\text { Prismatic hard } \\
\text { Al-can }\end{array}$ \\
\hline B & 2 & $\mathrm{LFP}\left(\mathrm{LiFePO}_{4}\right)$ & 20 & 3.2 & Pouch \\
\hline C & 5 & $\mathrm{LFP}\left(\mathrm{LiFePO}_{4}\right)$ & 7 & 3.2 & Pouch \\
\hline D & 9 & $\mathrm{LFP}\left(\mathrm{LiFePO}_{4}\right)$ & 3.2 & 3.2 & Cylindrical \\
\hline E & 5 & LFP $\left(\mathrm{LiFePO}_{4}\right)$ & 8 & 3.3 & Cylindrical \\
\hline F & 2 & NCA-LATP $\left(\mathrm{LiNiCOAlO}_{2}-\mathrm{LiAlTiPO}_{4}\right)$ & 30 & 2.3 & Pouch \\
\hline G & 2 & Laptop pack* & 5.6 & 11.1 & Cylindrical \\
\hline
\end{tabular}

Table 1. Details of the tested Li-ion battery cells. *Each laptop battery pack has 6 cells of type 18650; arranged 2 in parallel and 3 in series.

Of these $\mathrm{PF}_{5}$ is rather short lived. The toxicity of $\mathrm{HF}$ and the derivate hydrofluoric acid is well known ${ }^{22-24}$ while there is no toxicity data available for $\mathrm{POF}_{3}$, which is a reactive intermediate ${ }^{25}$ that will either react with other organic materials or with water finally generating $\mathrm{HF}$. Judging from its chlorine analogy $\mathrm{POCl}_{3} / \mathrm{HCl}^{24}, \mathrm{POF}_{3}$ may even be more toxic than HF. The decomposition of fluorine containing compounds is complex and many other toxic fluoride gases might also be emitted in these situations, however, this study focuses on analysis of HF and $\mathrm{POF}_{3}$.

Although a number of qualitative and semi-quantitative attempts have been made in order to measure HF from Li-ion batteries under abuse conditions, most studies do not report time dependent rates or total amounts of $\mathrm{HF}$ and other fluorine containing gases for different battery types, battery chemistries and state-of-charge (SOC). In some measurements reported, HF has been found, within limited SOC-variations, during the abuse of Li-ion battery cells ${ }^{15,16,26}$, as well as detected during the abuse of battery packs ${ }^{27}$. However, time-resolved quantitative HF gas emission measurements from complete Li-ion battery cells undergoing an abusive situation have until now only been studied to a limited extend; for a few SOC-values, including larger commercial cells ${ }^{28,29}$, a smaller-size commercial cell ${ }^{30}$ and a research cell (i.e. non-commercial cell) ${ }^{31}$. Time-resolved quantitative HF measurements on the gas release from complete electric vehicles including their Li-ion battery packs during an external fire have also been performed ${ }^{32}$. Other types of gas emissions from Li-ion cells during abuse have been the subject of a somewhat larger number of investigations ${ }^{33-41}$. Since the electrolyte typically is the primary source of fluorine, measurements of fluorine emissions from battery type electrolytes have been studied. For example, fire or external heating abuse tests have been performed on electrolytes ${ }^{42-46}$ and the quantitative amounts of $\mathrm{HF}$ and $\mathrm{POF}_{3}$ have been measured in some cases ${ }^{45,46}$. Other studies of electrolytes exposed to moderate temperatures, $50-85^{\circ} \mathrm{C}$, show the generation of various fluorine compound $s^{20,21,47-49}$ and some studies include both electrolyte and electrode material $^{50,51,52}$.

Our quantitative study of the emission gases from Li-ion battery fires covers a wide range of battery types. We found that commercial lithium-ion batteries can emit considerable amounts of HF during a fire and that the emission rates vary for different types of batteries and $\mathrm{SOC}$ levels. $\mathrm{POF}_{3}$, on the other hand, was found only in one of the cell types and only at $0 \%$ SOC. The use of water mist as an extinguishing agent may promote the formation of unwanted gases as in eqs (2)-(3) and our limited measurements show an increase of HF production rate during the application of water mist, however, no significant difference in the total amount of HF formed with or without the use of water mist.

Lithium-ion battery fire tests. The experiments were performed using an external propane burner for the purpose of heating and igniting the battery cells as described in the Methods section. Seven different types of batteries, type A-G, were investigated, from seven manufacturers and with different capacity, packaging type, design and cell chemistry, as specified in Table 1. Type A had a lithium cobalt oxide (LCO) cathode and carbon anode, types B to E had lithium-iron phosphate (LFP) cathode and carbon anode, type F had nickel cobalt aluminum oxide (NCA) and lithium aluminum titanium phosphate (LATP) electrodes while type G was a laptop battery pack with unspecified battery chemistry. All electrolytes contained $\mathrm{LiPF}_{6}$. Most of the cells were tested for different SOC levels, from fully charged, $100 \%$ SOC, to fully discharged, $0 \%$ SOC. The study included large-sized automotive-classed cells, i.e. series production cells of high industry quality, with long life time etc.

The heat release rate (HRR) and the emitted HF for B-type cells with different SOC values are shown in Fig. 1. Only the $100 \%$ SOC cells show several distinct peaks, corresponding to intense flares, when the cells vented and the emitted gas burn, for all other cells the heat release as a function of time is more smooth. These behaviors are reproducible also for the other tested cell types, e.g., only the $100 \%$ SOC cells show the more violent heat release peaks with intense flares.

The measurements of the gas emissions during the fire tests show that the production of HF is correlated to the increase in HRR although somewhat delayed. From Fig. $1 \mathrm{~b}$ it is evident that the higher SOC value, the higher values for the peak HF release rate. The total amount of HF varies considerably for the different battery types, see Fig. 2a. The amount of HF produced, expressed in $\mathrm{mg} / \mathrm{Wh}$, where $\mathrm{Wh}$ is the nominal battery energy capacity, is approximately 10 times higher for the cell with the highest values compared to the cells with the lowest values. The different relative amount of electrolyte and filler materials in the cells could be the simple explanation of this variation but information on those amounts are difficult to access for commercial batteries. The highest HF values are found for the pouch cells, a possible explanation would be that hard prismatic and cylindrical cells can build a 
a

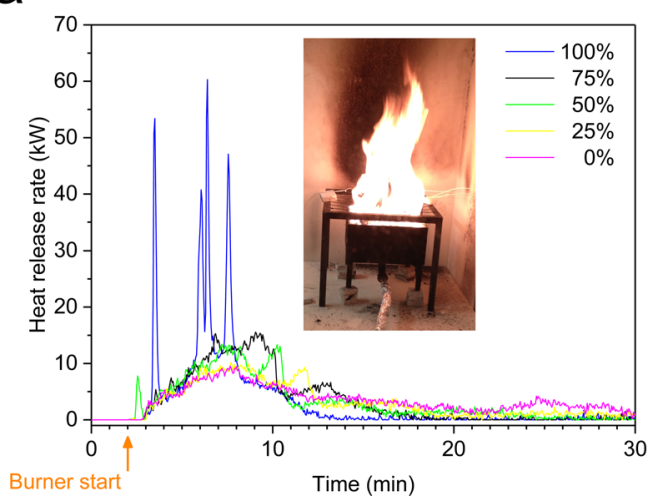

b

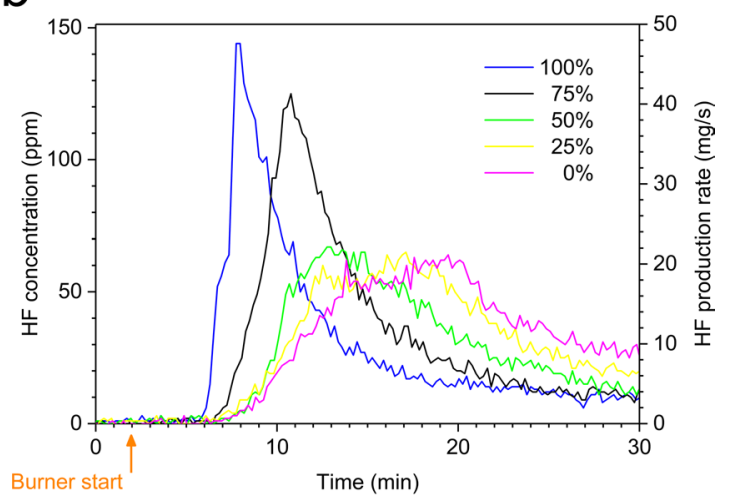

Figure 1. Results for type B cells, for $0-100 \%$ SOC with intermediate SOC-steps of $25 \%$, exposed to an external propane fire; (a) showing the heat release rate (burner HRR contribution is subtracted), the inset photo shows burning battery cells during the test; (b) showing the HF release both as the measured concentrations as well as the calculated HF production rates. The HF production rates are calculated from the measured HF concentration by the Ideal gas law taking into account the ventilation flow, see Methods. The starting time of the heating process is marked on the time axis.

a

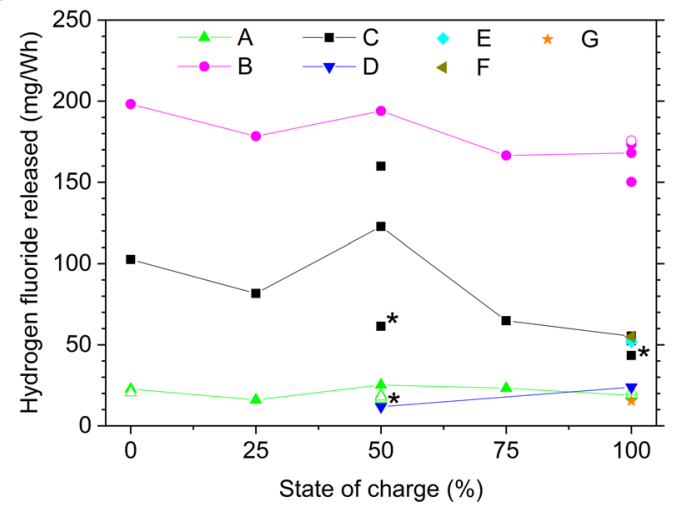

b

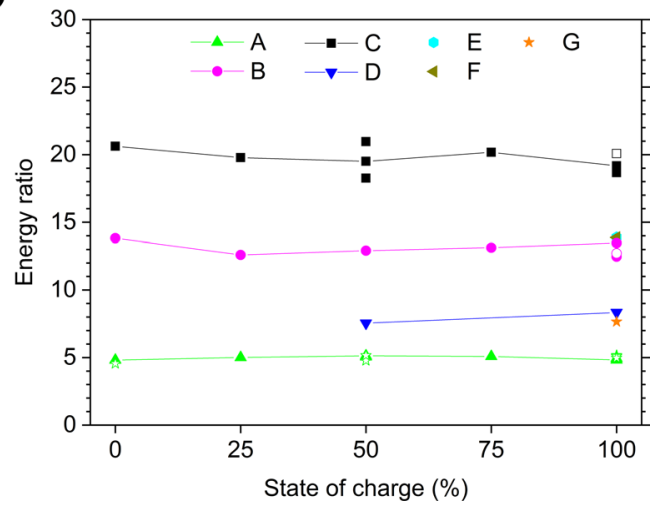

Figure 2. Total amount of HF measured by FTIR, normalized to nominal electrical energy capacity (a) and the energy ratio (b), for seven types of Li-ion battery cells and with various state of charge levels. Non-filled symbols indicate a repetition variant, e.g. applying water mist. The lines are intended as a guide for the eye. The energy ratio is a dimensionless value calculated by taking the total heat release from the battery fire divided by the nominal electrical energy capacity. Note that for $100 \%$ SOC the values are overlapping for type C, E and F as well as for type A, D and G in (a) and type B, E and F in (b). * Low value for type C at $50 \%$ and $100 \%$ SOC and type $\mathrm{D}$ at $50 \%$ SOC due to that a pre HF-saturation was not applied, therefore a part of the HF release was likely to be saturated in the gas sampling system, see Methods.

higher pressure before bursting, rapidly releasing a high amount of gases/vapors from the electrolyte. Due to the high velocity of the release and thus the short reaction time, combustion reactions might be incomplete and less reaction products might be produced. In the test involving type $\mathrm{G}$ the cylindrical cells were layered horizontally, thus having a different venting direction and possibly increased wall losses, which combined with a very energetic response, might suggest why HF was detected only from the filter analysis and not detected by FTIR-analysis. The tested pouch cells of type $\mathrm{B}$ and $\mathrm{C}$ burned for longer time and with less intensity. The pouch cell of type F, however, burned faster, possibly due to its different electrode materials. The SOC influence on the HF release was less significant and the trend in Fig. 2a shows higher HF values for $0 \%$ than for $100 \%$ SOC, however with clear peaks at $50 \%$ SOC. Although these results are reproducible, they are difficult to explain. In other studies ${ }^{30,31}$, significantly narrower in test scope, involving smaller-sized cells and using a somewhat different abuse method, it was found that the total amount of HF measured by real-time FTIR was higher for decreasing SOC (tests conducted at $100 \%, 50 \%$ and $0 \%$ SOC).

The HRR curve is used to calculate the total heat release (THR) which corresponds to the energy released from the burning battery. THR is obtained by integrating the measured HRR (with the burner contribution subtracted) over the complete test time. Fig. $2 \mathrm{~b}$ shows the energy ratio, that is how much energy is produced by the burning 


\begin{tabular}{|l|l|l|l|l|}
\hline Battery & $\begin{array}{l}\text { Nominal energy } \\
\text { capacity }(\mathbf{W h})\end{array}$ & $\begin{array}{l}\text { Normalized total HF detected } \\
\text { with FTIR (mg/Wh) }\end{array}$ & $\begin{array}{l}\text { Normalized maximum } \\
\text { HRR (W/Wh) }\end{array}$ & $\begin{array}{l}\text { Normalized THR } \\
\text { (kJ/Wh) }\end{array}$ \\
\hline A & 128 & $15-25$ & $243-729$ & $17-19$ \\
\hline B & 128 & $150-198$ & $78-633$ & $45-50$ \\
\hline C & 112 & $43-160$ & $116-491$ & $66-75$ \\
\hline D & 92 & $12-24$ & $207-315$ & $27-30$ \\
\hline E & 132 & 52 & 235 & 50 \\
\hline F & 138 & 55 & 384 & 50 \\
\hline G & 124 & 15 & 460 & 28 \\
\hline
\end{tabular}

Table 2. Main test results normalized to nominal energy capacity, when applicable including various SOClevels.

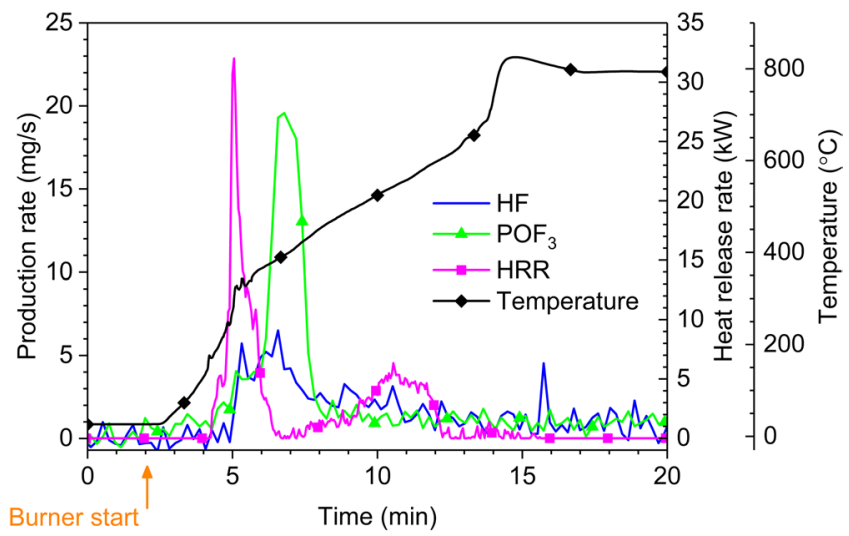

Figure 3. Results for a test with 5 type A cells at $0 \% \mathrm{SOC}$ showing $\mathrm{HF}$ and $\mathrm{POF}_{3}, \mathrm{HRR}$ and average surface temperature of the battery cells.

battery, compared to the amount of nominal electrical energy capacity a fully charged battery can deliver to an external circuit. The energy ratio is therefore a comparison between the chemical and the electrical energy of the $\mathrm{Li}$-ion battery cell. The energy ratio varies considerably for the different cell types but is approximately constant for each cell, independent of SOC level. There are some similarities in Fig. 2a and b for the pouch cells, type B and C, which give the highest values in both cases, although in reverse order. This might indicate a higher amount of combustibles, e.g. electrolyte, in these cells compared to the other cells. It is also interesting to see that the energy ratio varies significantly between the tested cells, ranging from 5 to 21 . This is important knowledge for fire protection and fire fighting. The energy ratio thus refers to a nominal fully charged battery while in normal use only a part of the SOC-window is used, for example half (50\%) of the SOC-window (corresponding to cycling the battery between e.g. $30 \%$ and $80 \%$ SOC). If instead, the total heat release divided by the used electric battery capacity in the specific application is considered, higher energy ratio values are obtained. A summary of the results is shown in Table 2.

The measured heat release from an overheated battery may include several aspects, e.g. the battery temperature increase and the combustion of released gases. Variations due to the type of battery cell, the initiation method, e.g. if the test is done as an external fire test, an external heating or an overcharge test, and the test method, e.g. access to ambient oxygen (inert, under-ventilated or well-ventilated fire), and the presence of an external igniter, can greatly affect the amount of measured heat release. Energy release from a internal cell event in a confined environment can, for example, be lower than the energy release from the same cell in case of external fire. Thus energy ratios published using other methods and other types of Li-ion cells can be significantly different ${ }^{7,52,53}$.

For all tested battert types and selected SOC-levels, $\mathrm{POF}_{3}$ could only be measured quantitatively for type A battery cells at $0 \%$ SOC. Repeated measurements confirmed the presence of $\mathrm{POF}_{3}$ only for type $\mathrm{A}$ and only for $0 \%$ SOC. No $\mathrm{POF}_{3}$ could thus be detected in any of the other tests. $\mathrm{POF}_{3}$ is an intermediate compound and the local combustion conditions in every test, will influence the amounts of $\mathrm{POF}_{3}$ generated. This shows the importance of investigating many different set-ups when evaluating emitted gases.

In Fig. 3 the HRR, the average surface temperature of the five cells as well as the $\mathrm{HF}$ and $\mathrm{POF}_{3}$ production rates are shown for type A cells at $0 \% \mathrm{SOC}$. The $\mathrm{POF}_{3}$ curve is less noisy than the HF curve due to different signal-to-noise ratios of the FTIR instrumentation at the different wavenumbers. There is a secondary peak in HRR approximately 5 minutes after the main heat event, this peak does not correspond to any peaks in the mass flow of $\mathrm{HF}$ or $\mathrm{POF}_{3}$. The explanation for this could be that the second peak in the heat release rate involves burning of mainly non-fluorine containing compounds. The temperature curve shows a rapid increase above the 


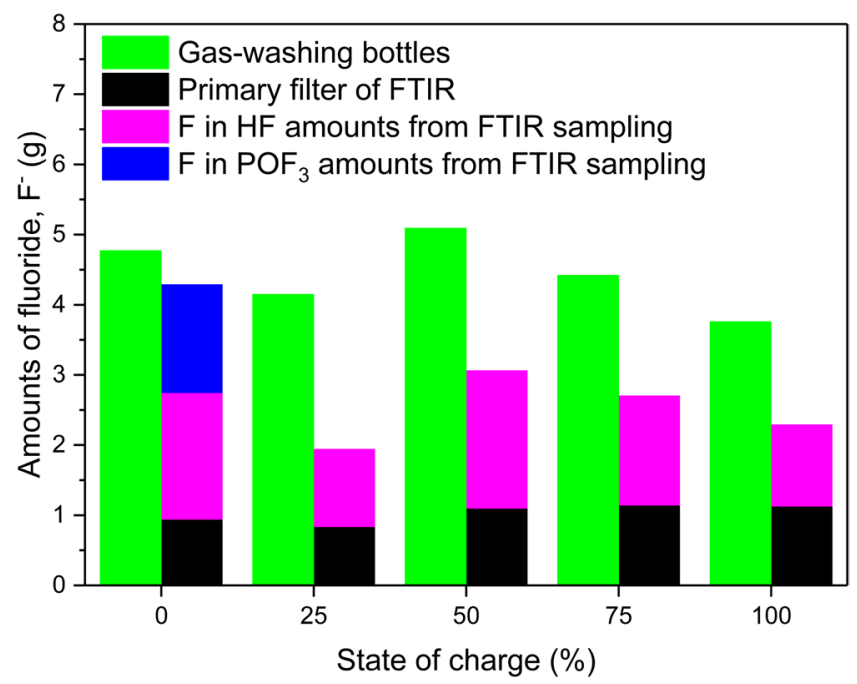

Figure 4. Total amount of measured fluoride, $\mathrm{F}^{-}$, for type A, for $0-100 \%$ SOC with intermediate steps of $25 \%$. The amount of $\mathrm{F}^{-}$from the FTIR is calculated from the measurement results for $\mathrm{POF}_{3}$ and HF, while the amount of fluoride from gas-washing bottles and primary filter analyses is measured as water soluble fluoride.

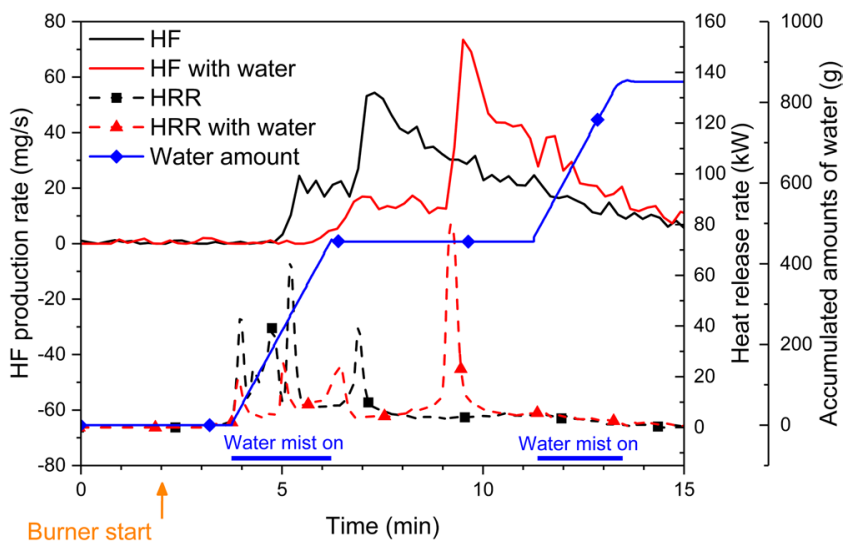

Figure 5. Results for type B cells at $100 \%$ SOC with and without the use of water mist.

melting temperature of the alumina cell case at about $660^{\circ} \mathrm{C}$. At these temperatures the alumina is molten and has formed a puddle on the burner bed beneath the battery cells. The thermal conditions in and around the thermocouples and the remains of the batteries have therefore changed considerably causing the apparent temperature increase.

In addition to the time resolved measurements with the FTIR, gas-washing bottles were used to determine the total fluorine content in the gas emissions during the tests. A comparison between the different measurement methods used can be seen in Fig. 4 for type A cells. Note that the FTIR measurements are performed only to detect $\mathrm{HF}$ and $\mathrm{POF}_{3}$, other fluoride compounds are not included. It is interesting to note that for $0 \%$ SOC the total amount of fluoride measured by the gas-washing bottle technique matches rather well with the FTIR and primary filter analysis. For other SOC values the fluoride content is higher from the gas-washing bottle measurements. Still, the general trend observed in the FTIR measurements for different SOC values is more or less confirmed by the gas-washing bottle measurements.

Gas-washing bottles were also used for some of the tests involving battery types B and C. These batteries showed higher amounts of released HF compared to type A. The ratio between the total values of released flouride from FTIR plus filter analysis and from the gas-washing bottles for type B and $\mathrm{C}$ was between 0.89 and 1.02, indicating a better correlation between FTIR and gas-washing bottles measurement when HF gas emissions are higher.

The total amount of $\mathrm{POF}_{3}$ measured by FTIR for type A at $0 \%$ SOC was $2.8 \mathrm{~g}$ (for 5 -cells) and $3.9 \mathrm{~g}$ (for 10 cells). Hence, the normalized total $\mathrm{POF}_{3}$ production was $15-22 \mathrm{mg} / \mathrm{Wh}$ of nominal battery energy capacity. Abuse studies measuring $\mathrm{POF}_{3}$ are few, Andersson et al. ${ }^{46}$ found both $\mathrm{HF}$ and $\mathrm{POF}_{3}$ when burning mixtures of propane and Li-ion battery electrolytes with a $\mathrm{HF}: \mathrm{POF}_{3}$ production ratio between 8:1 and 53:1. Besides $\mathrm{HF}$ and $\mathrm{POF}_{3}$ measurements, several distinct non-assigned peaks were found in the FTIR measurements, e.g. at $1027 \mathrm{~cm}^{-1}$ 


\begin{tabular}{|l|l|l|l|l|l|l|}
\hline \multirow{2}{*}{ Battery } & \multirow{2}{*}{ SOC $(\%)$} & $\begin{array}{l}\text { Number } \\
\text { of tests }\end{array}$ & From FTIR & $\begin{array}{l}\text { From gas-washing } \\
\text { bottles }\end{array}$ & $\begin{array}{l}\text { Normalized maximum } \\
\text { HRR (W/Wh) }\end{array}$ & $\begin{array}{l}\text { Normalized } \\
\text { THR (kJ/Wh) }\end{array}$ \\
\hline \multirow{3}{*}{ A } & 100 & 6 & $19.8 \pm 1.2[3]$ & $29.1 \pm 3.1[5]$ & $612 \pm 102$ & $18.1 \pm 0.46$ \\
\cline { 2 - 5 } & 50 & 7 & $18.5 \pm 3.9[6]$ & $36.7 \pm 3.3[6]$ & $416 \pm 39[6]$ & $18.0 \pm 0.61[6]$ \\
\cline { 2 - 5 } & 0 & 2 & $21.6 \pm 1.5$ & $38.3 \pm 1.6$ & $214 \pm 53$ & $16.8 \pm 0.66$ \\
\hline B & 100 & 4 & $166.8 \pm 11.5$ & $191.3 \pm 11.3[2]$ & $538 \pm 77$ & $46.9 \pm 1.9$ \\
\hline \multirow{2}{*}{ C } & 100 & 3 & $53.9 \pm 2.0[2]^{*}$ & N/A & $461 \pm 27$ & $69.5 \pm 2.6$ \\
\cline { 2 - 5 } & 50 & 3 & $141.3 \pm 26.3[2]^{*}$ & N/A & $149 \pm 5$ & $70.5 \pm 4.9$ \\
\hline
\end{tabular}

Table 3. Detailed results for all available repetitions. Values presented as mean values followed by the standard deviation, in case the data parameter was not measured in all tests the value in bracket declares the number of available tests used for the specific data parameter value. *For FTIR data for battery type $\mathrm{C}$, one data point of $50 \%$ and one data point at $100 \%$ SOC are excluded as outliers since they were low due to that a pre HFsaturation was not applied in the test, see Methods.

and $1034 \mathrm{~cm}^{-1}$, which have also been seen in other studies ${ }^{46}$. They are compatible with the typical C-O stretching energies of low molecular weight alcohols in gas phase but also with in-plane stretching of aromatic compounds. This indicates the complexity and the limited knowledge in this area.

Water mist measurements. In order to study the effects of water on gas emissions, fire tests have also been performed where a water mist was applied during the fire. The reason for this experiment is that water is the preferred extinguishing agent for a lithium-ion battery fire. The intention in this study was however not to extinguish the fire completely. One potential problem regarding the use of water mist is that the addition of water may, in principle, increase the rate of formation of HF, see Eqs (2) and (3).

Figure 5 shows the results for type B cells with and without exposure to water mist, note that both the HRR and HF production are delayed when water mist is used. In this limited study, the peak of the HF production rate increased by $35 \%$ when using water, however no significant change in the total amounts of the HF release could be seen. A similar result has been reported in a previous study ${ }^{28}$. The water mist was applied during two different periods of time, as marked in Fig. 5, adding a total of $851 \mathrm{~g}$ of water in the reaction zone, however, several other large sources of water were also present in the experiment, i.e. water production from the propane combustion and from humidity in the air. The water mist is cooling the fire and the top surface of the pouch cell was for some time partly covered with liquid water; this is the reason that the battery fire is delayed as seen in Fig. 5 . The water mist might actually also clean the air by collecting fume particles and HF can be bound to water droplets, thus possibly lowering the amount of HF in the smoke duct and increasing the non-measured amount of very toxic hydrofluoric acid on the test area surfaces (e.g. walls, floor, smoke duct walls).

\section{Repeatability}

Repeated tests were performed for battery types A-C for selected SOC-levels. Some of the repetitions included a variant, e.g. including water mist; see Methods. In Fig. 2 all available test data are presented. Since the test repetitions are not clearly observable in Fig. 2 the results are also presented in Table 3 showing the mean values and standard deviations and the number of performed tests. While the ranges in Table 2 include data for all tested SOC-values, Table 3 shows test data for repeated measurements including repetition variants.

Figure 6 shows the repeatability results for four tests of battery type B for 100\% SOC. The time evolution of HRR varies in the fire tests as seen in Fig. 6a. In fire tests there are always natural variations, however comparing the tests with $100 \%$ SOC, in Fig. 6a, with those with lower SOC-values presented in Fig. 1a, the repeatability of the $100 \%$ SOC tests is significant. The third repetition (black line) in Fig. 6 a is delayed due to that it included an application of water mist, as discussed above. Although the appearance of the HRR plots of the four tests differs in Fig. $6 \mathrm{a}$ the THR (the integrated HRR) values are rather similar. Fig. $6 \mathrm{~b}$ shows the HF release for the same four tests of type B at $100 \%$ SOC. Repetition 2 and 3 were performed in the third test period, without secondary FTIR filter, and therefore Repetition 2 occurs earlier while Repetition 3 is delayed due to the applied water mist, as discussed above. For the four tests of type B at $100 \%$ SOC the mean value of the total FTIR detected HF release is $166.8 \mathrm{mg} / \mathrm{Wh}$ with a standard deviation of $11.5 \mathrm{mg} / \mathrm{Wh}$, as seen in Table 3. Comparing Fig. $1 \mathrm{~b}$ and Fig. 6b, shows that for $100 \%$ SOC the HF release is faster and reaches a higher value. Repetition 1 in Fig. $6 \mathrm{~b}$ shows lower HF release peak values, however, the total HF release value from the FTIR measurement of $168 \mathrm{mg} / \mathrm{Wh}$ is close to the average value $(166.8 \mathrm{mg} / \mathrm{Wh}$, as seen in Table 3$)$.

\section{Conclusions}

This study covered a broad range of commercial Li-ion battery cells with different chemistry, cell design and size and included large-sized automotive-classed cells, undergoing fire tests. The method was successful in evaluating fluoride gas emissions for a large variety of battery types and for various test setups.

Significant amounts of HF, ranging between 20 and $200 \mathrm{mg} / \mathrm{Wh}$ of nominal battery energy capacity, were detected from the burning Li-ion batteries. The measured HF levels, verified using two independent measurement methods, indicate that HF can pose a serious toxic threat, especially for large Li-ion batteries and in confined environments. The amounts of HF released from burning Li-ion batteries are presented as $\mathrm{mg} / \mathrm{Wh}$. If extrapolated for large battery packs the amounts would be $2-20 \mathrm{~kg}$ for a $100 \mathrm{kWh}$ battery system, e.g. an electric 
a

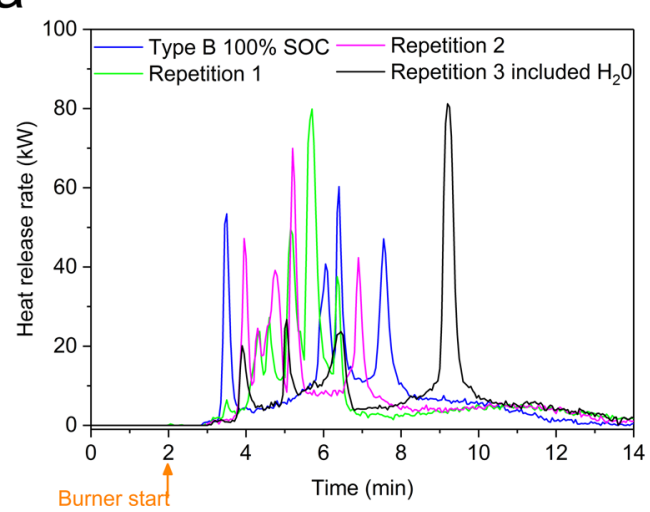

b

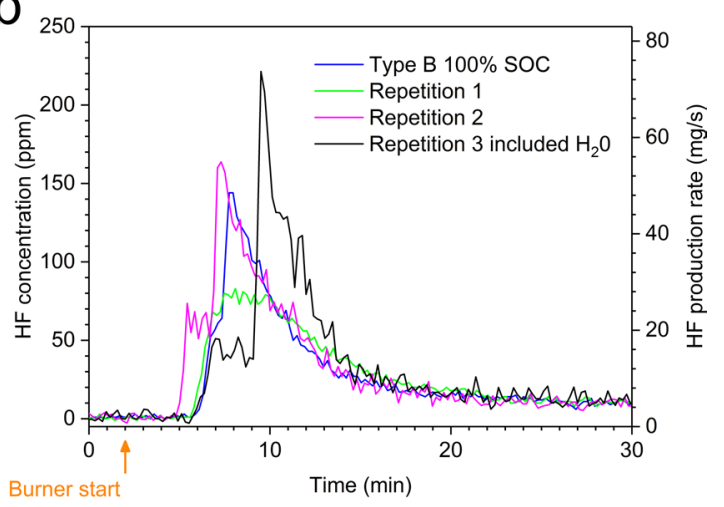

Figure 6. Repeatability for four tests of type B cells at 100\% SOC, (a) shows the heat release rate (burner HRR contribution is subtracted) and (b) shows the HF release, both as the measured concentrations as well as the calculated HF production rates.

vehicle and $20-200 \mathrm{~kg}$ for a $1000 \mathrm{kWh}$ battery system, e.g. a small stationary energy storage. The immediate dangerous to life or health (IDLH) level for HF is $0.025 \mathrm{~g} / \mathrm{m}^{3}(30 \mathrm{ppm})^{22}$ and the lethal 10 minutes HF toxicity value (AEGL-3) is $0.0139 \mathrm{~g} / \mathrm{m}^{3}(170 \mathrm{ppm})^{23}$. The release of hydrogen fluoride from a Li-ion battery fire can therefore be a severe risk and an even greater risk in confined or semi-confined spaces.

This is the first paper to report measurements of $\mathrm{POF}_{3}, 15-22 \mathrm{mg} / \mathrm{Wh}$, from commercial Li-ion battery cells undergoing abuse. However, we could only detect $\mathrm{POF}_{3}$ for one of the battery types and only at $0 \% \mathrm{SOC}$, showing the complexity of the parameters influencing the gas emission. No $\mathrm{POF}_{3}$ could be detected in any of the other tests.

Using water mist resulted in a temporarily increased production rate of HF but the application of water mist had no significant effect on the total amount of released HF.

The research area of Li-ion battery toxic gas emissions needs considerable more attention. Results as those presented here are crucial to be able to conduct a risk assessment that takes toxic HF gas into account. The results also enable strategies to be investigated for counteractions and safety handling, in order to achieve a high safety level for Li-ion battery applications. Today we have a rapid technology and market introduction of large Li-ion batteries but the risks associated with gas emissions have this far not been possible to take into consideration due to the lack of data.

\section{Methods}

Seven types of Li-ion batteries were exposed to an external propane fire. Fire characteristics, gas emissions, battery temperatures and cell voltages were measured. In total 39 fire tests were conducted of which 20 were within the base test matrix, 19 were repeated measurements of selected battery types and SOC-levels of which 10 included a variant, e.g. water mist for fire-fighting. The amounts of emitted fluoride gases were measured with two parallel and independent techniques, FTIR (time resolved concentration measurements and total values achieved by integration of the time resolved curve) and gas-washing bottles (total values). The experimental setup is schematically shown in Fig. 7. The gas collecting system and measurement system of the Single Burning Item (SBI) method (EN 13823 ${ }^{54}$, which is normally used for reaction-to-fire classification of construction products according to EN 13501-1 ${ }^{55}$ was used in the tests. The tests were performed in three different test periods; the second test period was conducted about 1 year after the first and the third test period was conducted about 2.5 years after the first. Each test period involved several days of testing. The measurement equipment, as specified in the text below, was somewhat varying between the three test periods.

Batteries. Six different types of Li-ion battery cells, type A-F, and one Li-ion battery pack, type G, were tested as seen in Table 1 . The number of cells used in each test was varied in order to achieve similar electrical energy capacity per test. The batteries were placed on wire gratings just above a $16 \mathrm{~kW}$ propane burner. The wire grating was made of steel wire about $2 \mathrm{~mm}$ thick over a surface of about $300 \times 300 \mathrm{~mm}$. The quadrants of the grating were $40 \times 100 \mathrm{~mm}$. The cells were not electrically connected to each other (except the laptop packs of type G, see note in Table 1). Type A-F was pure battery cells while type $\mathrm{G}$ was a complete laptop battery pack which included plastics box, electronics and cables. The chemical content of the polymer materials in the auxiliary components of the battery pack of battery type $\mathrm{G}$ is not known. It is possible, however not likely, that fluorine was included in some of the components, which in that case could have resulted in the production of HF. For battery type A, 5 cells/test was used except in two variant tests in which 10 cells/test were used.

The influence of different state of charge was investigated, for some battery types the complete SOC-window ranging from $0 \%$ to $100 \%$, with intermediate steps of $25 \%$, was investigated. The SOC levels included for each battery type and the numbers of repetitions per test type, i.e. the fire test matrix, is seen in Table 4 . All parameters were not measured in all of the tests. Measurement of HRR and corresponding THR was conducted in 38 tests, FTIR in 35 tests and gas-washing bottles were used in 19 tests. 


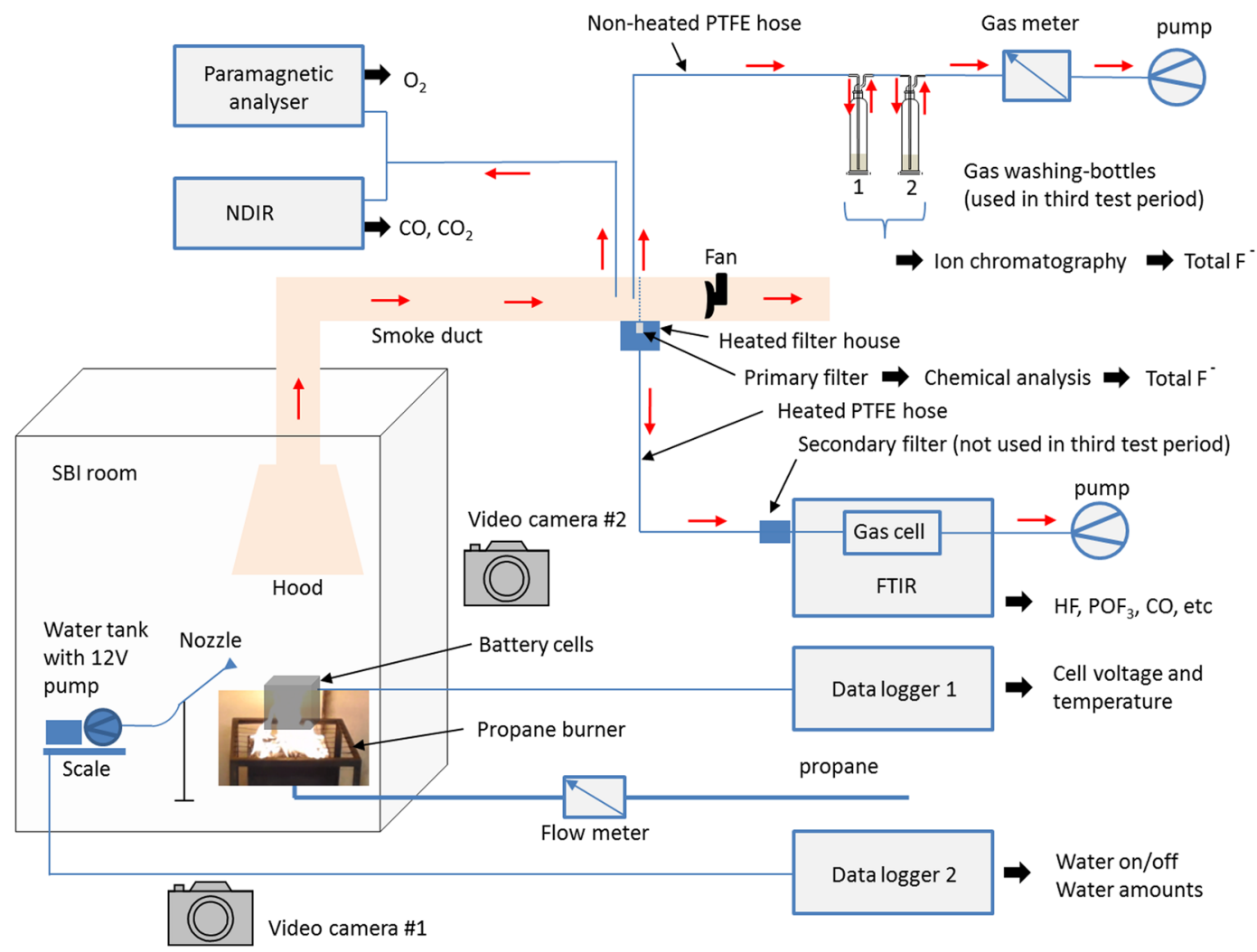

Figure 7. Schematic illustration of the experimental setup.

\begin{tabular}{|c|c|c|c|c|c|c|}
\hline \multirow[b]{2}{*}{ Battery } & \multicolumn{5}{|c|}{ Number of tests per SOC-level } & \multirow[b]{2}{*}{ Number of tests } \\
\hline & $0 \%$ & $25 \%$ & $50 \%$ & $75 \%$ & $100 \%$ & \\
\hline A & $1+1^{*}$ & 1 & $3+4^{*}$ & 1 & $3+3 *$ & 17 \\
\hline $\mathrm{B}$ & 1 & 1 & 1 & 1 & $3+1 *$ & 8 \\
\hline $\mathrm{C}$ & 1 & 1 & 3 & 1 & $2+1 *$ & 9 \\
\hline $\mathrm{D}$ & & & 1 & & 1 & 2 \\
\hline $\mathrm{E}$ & & & & & 1 & 1 \\
\hline $\mathrm{F}$ & & & & & 1 & 1 \\
\hline G & & & & & 1 & 1 \\
\hline Total number of tests & & & & & & 39 \\
\hline
\end{tabular}

Table 4. Detailed test matrix of the fire tests. *repetition includes a variant, e.g. water mist or $2 \times 5$-cell-pack (for battery type A).

The selected SOC level in each test was set using a charge/discharge procedure using ordinary laboratory equipment as well as dedicated battery test equipment, i.e. a Digatron battery tester and Metrohm Autolab PGSTAT302N with 20 A booster module. The cells were first fully charged by constant current followed by constant voltage (CC-CV) according to the manufacturer's instructions. For cells intended for tests with less than $100 \%$ SOC, the cell was discharged to the selected SOC level, using constant discharge current (CC). A relative low current rate, about $\mathrm{C} / 5$, was used and voltage and current rates were within the manufacturer limits. In most cases each battery type was tested during the same test period. However, the tests for type $\mathrm{C}$ and $\mathrm{D}$ were split in several test periods, for type $\mathrm{C}$ repetitions on $50 \%$ SOC were conducted in all three test periods, and for type B repetitions at $100 \%$ SOC were made in two test periods, the latter one included a water mist test.

All batteries were unused and the calendar life time of the cells before the tests were approximately 6-12 months for type A, F and G and between approximately 2-3 years for type B-E. The pouch cells; type B, C and $\mathrm{F}$ was mechanically tied together with steel wires $(0.8 \mathrm{~mm}$ diameter $)$. The type A hard prismatic cells were tight together in packs of five cells, "5-cell-pack", using steel straps $(1 \times 13 \mathrm{~mm})$. The hard prismatic and cylindrical cells were placed in boxes to protect test personnel from potential projectile hazards in case of cell explosions due to excessive pressure. The 5-cell-pack of type A was placed standing up, with the cell safety vents releasing straight upright in direction to the hood and smoke duct, inside a custom-made steel-net-box, see Fig. 8. Additionally, the 5-cell-pack of type A was fastened to the bottom of the steel-net-box with steel wire ( $0.8 \mathrm{~mm}$ diameter) in the 


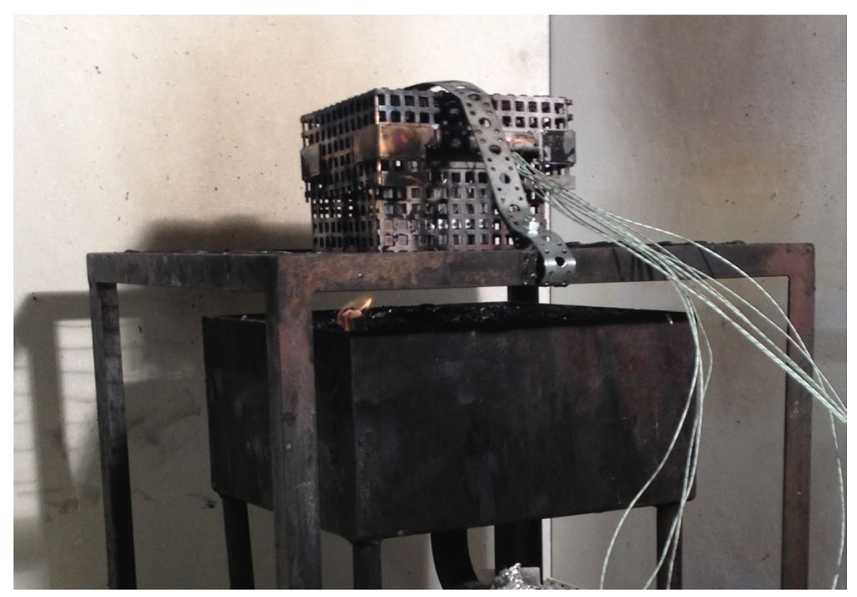

Figure 8. Photo of test type A, showing the 5-cell-pack inside a steel-net-box placed on the wire gratings. The sand bed for the propane burner is underneath the wire grating, a pilot flame (seen in front left corner of the burner) is used to ignite the propane gas.

corners to avoid it moving around due to e.g. explosion/rupture/venting. Type D and E cells were placed standing up in custom-made boxes made of non-combustible silica board and steel net at the top and bottom. Type G was placed in a steel net. The protective boxes and steel net were fastened in the wire gratings with steel wire and steel straps to avoid movement due to response to the fire. Care was taken to avoid external short circuiting when placing the battery on the wire gratings as well as avoiding accidental external electrical inter-cell-connections, e.g. for pouch cells the electrical tab terminals were cut. Still the battery test setup allowed that the separators and electrical insulation in the cells could melt due to the heat exposure which could cause various internal and external electrical contacts.

The battery surface temperature was measured with several type K thermocouples; the number of sensors varied for the different battery types. Battery cell surface temperature values presented in this paper are average values over the cell. Cell voltages were measured for type A, B, C and F battery tests. Cell voltage and thermocouple readings was sampled with $1 \mathrm{~Hz}$ using two types of data loggers, Agilent $34972 \mathrm{~A}$ using an Agilent $34902 \mathrm{~A}$ reed multiplexer module (for the third test period) and Pico Technology ADC-24 (for the first and second test period).

Test procedure. The propane burner was started 2 minutes into each test, as indicated with arrows in the result figures in the paper. The burner was active as long as there was a heat contribution from the burning batteries; therefore, the burner was active for different durations of time for different batteries and SOC-levels. When the heat release from the batteries was no longer detectable, the power of the propane burner was doubled, i.e. to $32 \mathrm{~kW}$, in order to be sure to fully burn out any residues of the batteries, for increased personnel safety. The fire emissions were collected in the hood and transferred in the smoke duct having a ventilation flow of $0.4 \mathrm{~m}^{3} / \mathrm{s}$, with the exception that $0.6 \mathrm{~m}^{3} / \mathrm{s}$ was used in two tests with $100 \%$ SOC for type C. For these cases the values were scaled down to the lower flow values making the results from the two flow rates comparable. The SBI-room, see Fig. 7, had a ventilation inlet from an adjacent indoor laboratory hall (which had fresh air inlet from the ventilation system in the building), supplying ambient air with temperature about $20^{\circ} \mathrm{C}$ entering beneath the propane burner. We consider the amount of ambient air to be sufficient to provide an oxygen-rich environment and thereby consider the battery fire as well-ventilated. However for some tests, during the rapid and energetic gas outbursts, a full combustion might not have occurred in these short time periods.

All tests were video recorded and for the majority of the tests an additional camera was used set at 90 degree angle from the other video camera, allowing simultaneous recording from two sides of the battery fire.

A part of the smoke duct flow was sampled to a Servomex 4100 Gas purity analyser where the oxygen content was measured by a paramagnetic analyser and $\mathrm{CO}$ and $\mathrm{CO}_{2}$ were measured by a non-dispersive infrared sensor (NDIR). By combing these two measurements, the heat release rate (HRR) is calculated using the oxygen consumption method corrected by $\mathrm{CO}_{2}{ }^{54}$. Each test day started with a blank test, i.e. using only the propane burner, to measure the HRR of the burner alone and measure blanks for FTIR and gas-washing bottles. In the presented HRR values of the battery tests the burner contribution to the HRR (about $16 \mathrm{~kW}$, with slight daily variations, established by the blank tests) has been subtracted. The combined expanded uncertainty is $\pm 5 \mathrm{~kW}$ for the HRR-values. By integrating the HRR values over the entire test, subtracting the HRR from the burner, the total heat release (THR) from the battery cells could be established. The oxygen consumption method is common in fire calorimetry, however when using it with batteries, the joule heating from electrical discharge within the cells is not accounted for, therefore the values of HRR and THR do not include the Joule heating. During the external fire tests, it is difficult to measure how much a battery cell is electrically discharged when the separator is melting. The energy ratios presented in Fig. $2 \mathrm{~b}$ do not include any Joule heating as clearly stated by its definition. For $0 \%$ SOC the influence from Joule heating is in principle zero, however small amounts of joule heating might possibly be liberated when going to zero voltage even though other processes might occur. Li-ion cells can also release oxygen during thermal runaway and this could affect the measured $\mathrm{O}_{2}$ levels. The amount of oxygen release varies 


\begin{tabular}{|l|l|}
\hline Spectral bands $\left(\mathbf{c m}^{-1}\right)$ & Type of band \\
\hline $\mathrm{POF}_{3}$ & P-F symmetric stretching mode ${ }^{20}$ \\
\hline $868-874$ & P-O stretching mode \\
\hline $1413-1418$ & HF R-branch stretching mode \\
\hline HF & HF R-branch stretching mode \\
\hline $4172-4175$ & \\
\hline $4202-4203$ &
\end{tabular}

Table 5. FTIR spectral band used for measurements of $\mathrm{POF}_{3}$ and $\mathrm{HF}$.

for different electrode materials, e.g. LFP typically releases less oxygen than LCO. However, the ventilation flow is large and the $\mathrm{O}_{2}$ released from the battery cells is regarded as negligible.

Gas measurements. Besides the gas measurements in the SBI apparatus, measurements of gases were also conducted by online Fourier transform infrared spectroscopy (FTIR). The FTIR offers broad and diverse spectra of gases, the focus was however on fluoride gas emissions. The FTIR used was a Thermo Scientific Antaris IGS analyzer (Nicolet) with a gas cell. The gas cell was heated to $180^{\circ} \mathrm{C}$ and had a volume of $0.2 \mathrm{~L}, 2.0 \mathrm{~m}$ path length and a cell pressure of $86.7 \mathrm{kPa}$ which was maintained during the tests. The spectral resolution of the FTIR was $0.5 \mathrm{~cm}^{-1}$ (accuracy $0.01 \mathrm{~cm}^{-1}$ ) and $10 \mathrm{scans}$ where used to collect a spectrum every $12 \mathrm{~s}$, giving both accurate intensity, as well as relatively rapid measurements with its five spectrum per minute rate. A part of the duct flow, taken along the full duct pipe width (in the mid height of the pipe) from around 15 sampling holes (about $2 \mathrm{~mm}$ diameter, directed opposite to flow, pipe end was closed), was taken to online FTIR measurement. This sub-flow was extracted through a primary filter inside a heated filter house $\left(180^{\circ} \mathrm{C}\right)$ and then extracted through an $8.5 \mathrm{~m}$ sampling PTFE hose, heated to $180^{\circ} \mathrm{C}$, and then through a secondary filter and finally through the gas cell of the FTIR. The sub-flow was selected to be $3.5 \mathrm{~L} / \mathrm{min}$ using a pump located after the FTIR gas cell. Between each test the FTIR sampling system was flushed with $\mathrm{N}_{2}$ gas and a new background spectrum was measured. There is a natural delay time between the FTIR and the heat release measurement. In order to time synchronize them the $\left(\mathrm{CO}_{2}\right.$ measurements from both the FTIR and the NDIR) part of the heat release rate measurement, were overlayed.

One primary filter (M\&C ceramic filter, type "F-2K") was used per test and was chemically analysed for fluoride content after the test. It is known that HF may be partly adsorbed by this type of filter ${ }^{56}$. The fluoride amount absorbed by the filter was determined by leaching the filter in an ultrasonic water bath for at least 10 min and thereafter the fluoride content in the water was measured by ion chromatography with a conductive detector, according to the method B.1 (b) of the SS-ISO 19702:2006 Annex B standard. The amount of HF is calculated by assuming that all fluoride ions present in the filter derives from HF. The secondary filter (M\&C sintered steel filter), heated to $180^{\circ} \mathrm{C}$, was the same in all tests in the first and second test period. In the third test period the secondary filter was removed in order to decrease delay time and losses. The third test period started with burning 10 cells of type A in order to saturate the FTIR sampling system with HF and it was conducted because in the first and the second test period the first tests had indicated low HF values, HF was potentially lost during saturation of the gas collecting system.

The FTIR was calibrated ${ }^{29,57}$ for $\mathrm{HF}$ and $\mathrm{POF}_{3}$. The minimum detection limit (MDL) for HF was $1.7 \mathrm{ppm}$ and the limit of quantification (LOQ) was established to $5.7 \mathrm{ppm}$. The detection limit for $\mathrm{POF}_{3}$ was $6 \mathrm{ppm}^{29}$. $\mathrm{PF}_{5}$ was also qualitatively detectable by the FTIR $^{29}$ but not quantitatively calibrated. A classical least square (CLS) method was used for the quantification of $\mathrm{HF}$ and $\mathrm{POF}_{3}$ using the spectral bands specified in Table 5 . The relative error of the HF prediction is lower than 10 rel-\%.

For all measurements, except type G, the measured ppm levels of HF were above the detection level. For $\mathrm{POF}_{3}$, the maximum concentration was $11 \mathrm{ppm}$ (5-cells) and $19 \mathrm{ppm}$ (10-cells).

When the FTIR measurement stopped, HF levels were, in some of the tests, still somewhat above the detection limit, even though no HRR contribution was measured from the batteries. It is also possible that the HF was temporarily clogged in the sampling system. Some HF might not have been collected in the measurements and the effect of this error is largest for the batteries that give the lowest values. Thus the reported values might underestimate the released gas emissions.

In order to further improve the accuracy of the FTIR measurements, a data offset determination and a subsequent adjustment of the HF values was performed. The improvement was greatest for tests with lower concentrations, closer to the MDL value, e.g. type A with 5 cells with low values during relatively short periods of time. With 10 cells per test, the type A batteries gave higher signal-to-noise levels. The FTIR measurements started around 8 minutes before the burner was started. The calculated average HF ppm noise level was treated as an offset that had both negative and positive values, ranging from extreme values of about -2 to $3.5 \mathrm{ppm}$. This offset was compensated for by assuming a constant offset value and adding positive or negative offset values to the total $\mathrm{HF}$ release value. Note that the reported concentration values in ppm are only valid for the measurements in the smoke duct of our specific test equipment and method. The $\mathrm{HF}$ and $\mathrm{POF}_{3}$ concentration values (in ppm) were used for calculating the corresponding production rates (in $\mathrm{mg} / \mathrm{s}$ ) using the ideal gas law and taking into account the measured ventilation flow rate in the smoke duct.

In the third test period the total amounts of water soluble fluorides were determined using gas-washing bottle technique. This was made in order to validate the results from the FTIR measurements with a separate measurement technique. The water soluble fluorides were collected in the bottles and the amount of HF was calculated by assuming that all fluoride ions present derives from HF. The sample gas was extracted from the center of 
the smoke duct using a non-heated $6 \mathrm{~mm}$ (o.d.) diameter PTFE sampling tube with a length of about $1.5 \mathrm{~m}$. The sampling was made using two gas-washing bottles connected in series each containing $40 \mathrm{~mL}$ of an alkaline buffer solution $\left(20 \mathrm{mM} \mathrm{Na}_{2} \mathrm{CO}_{3} / 20 \mathrm{mM} \mathrm{NaHCO}_{3}\right)$. The second bottle was used to capture any losses from the first bottle. The sampling flow was 1.0 normal-L/min and the total sampled volume during a test was measured by a calibrated gas volume meter. The sampling flow rate was checked before the start of each test using a Gilian Gilibrator-2 NIOSH Primary Standard Air Flow Calibrator gas flow meter. The procedure during a test was to continuously sample during the full test time. When the test was completed, the sampling tube was disconnected from the exhaust duct to allow rinsing of the tube with buffer solution, about $30 \mathrm{~mL}$ in the first gas-washing bottle, to collect any fluoride deposited on the inner walls of the tubing, in order to minimize losses in the tube. Since the tube was rinsed, heating of the tube was not necessary (any condensation in tube was collected anyhow). Analysis of fluorine content of the absorption solutions was made using High Performance Ion Chromatography (HPIC). The contents of the two gas-washing bottles were analyzed separately. The bottles were rinsed with distilled water between each test in order to minimize any interference between tests.

Water mist test. In the water mist tests, a custom-made equipment was constructed, including a $12 \mathrm{~V}$ automotive pump and water container which was placed on a scale measuring the weight of the water. The scale readings and the on/off manual switching (of the $12 \mathrm{~V}$ ) was recorded with $1 \mathrm{~Hz}$ using Pico Technology ADC-24 with a custom-made LabVIEW program. The water mist was sprayed on or above the batteries using a metal nozzle. In order for precise time synchronization, the on/off $12 \mathrm{~V}$ signal was recorded by both data loggers (data logger 1 and data logger 2). A blank test, i.e. using only the propane burner and without batteries, was performed in order to calibrate the setup. The water flow was around $190 \mathrm{~g}$ water per min and consisted of deionized water.

\section{References}

1. Samsung Note 7: Press Conference Details, Samsung US, Our safety promise, http://www.samsung.com/us/explore/committed-toquality/?CID = van-brd-brd-0119-10000141, Date of access: 06/04/2017.

2. Prigg, M. Nasa reveals shocking video of secretive military 'RoboSimian' EXPLODING as its batteries catch fire (2016), http://www. dailymail.co.uk/sciencetech/article-3883158/Nasa-reveals-shocking-video-secretive-military-RoboSimian-EXPLODING-batteriescatch-fire.html, Date of access: 06/04/2017.

3. Aircraft Serious Incident Investigation Report, JA804A. Japan Transport Safety Board (2014), Available online: http://www.mlit. go.jp/jtsb/eng-air_report/JA804A.pdf, Date of access: 13/02/2017.

4. Auxiliary Power Unit Battery Fire, Japan Airlines Boeing 787-8, JA829J, Boston, Massachusetts; NTSB/AIR-14/01. National Transportation Safety Board (2014), Available online: http://www.ntsb.gov/investigations/AccidentReports/Reports/AIR1401.pdf, Date of access: 13/02/2017.

5. Chevrolet Volt battery incident overview report, National Highway Traffic Safety Administration (NHTSA), DOT HS 811573 (2012).

6. Doughty, D. \& Roth, E. P. A general discussion of Li ion battery safety. The Electrochem. Soc. Interface, summer 2012, 37-44 (2012).

7. Larsson, F. \& Mellander, B.-E. Abuse by external heating, overcharge and short circuiting of commercial lithium-ion battery cells. J. of The Electrochem. Soc. 161(10), A1611-A1617 (2014).

8. Larsson, F., Andersson, P. \& Mellander, B.-E. Are electric vehicles safer than combustion engine vehicles? in Systems perspectives on Electromobility (eds. Sandén, B. \& Wallgren, P.) 33-44 (Chalmers University of Technology, 2014).

9. Finegan, D. P. et al. In-operando high-speed tomography of lithium-ion batteries during thermal runaway. Nat. Commun. 6, 6924 (2015).

10. Larsson, F., Andersson, P. \& Mellander, B.-E. Lithium-ion battery aspects on fires in electrified vehicles on the basis of experimental abuse tests. Batteries 2, 9 (2016).

11. Lopez, F. L., Jeevarajan, J. A. \& Mukherjee, P. P. Experimental analysis of thermal runaway and propagation in lithium-ion battery modules. J. of The Electrochem. Soc 162(9), A1905-A1915 (2015).

12. Lamb, J., Orendorff, C. J., Steele, L. A. M. \& Spangler, S. W. Failure propagation in multi-cell lithium-ion batteries. J. of Power Sources 283, 517-523 (2015).

13. Larsson, F., Anderson, J., Andersson, P. \& Mellander, B.-E. Thermal modelling of cell-to-cell fire propagation and cascading thermal runaway failure effects for lithium-ion battery cells and modules using fire walls. J. of The Electrochem. Soc. 163(14), A2854-A2865 (2016).

14. Lebedeva, N. P. \& Boon-Brettz, L. Considerations on the chemical toxicity of contemporary Li-ion battery electrolytes and their components. J. of The Electrochem. Soc. 163(6), A821-A830 (2016)

15. Sun, J. et al. Toxicity, a serious concern of thermal runaway from commercial Li-ion battery. Nano Energy 27, 313-319 (2016).

16. Nedjalkov, A. et al. Toxic gas emissions from damaged lithium ion batteries-analysis and safety enhancement solution. Batteries $\mathbf{2}$, 5 (2016).

17. Liu, K. et al. Electrospun core-shell microfiber separator with thermal-triggered flame-retardant properties for lithium-ion batteries. Sci. Adv. 3, el601978 (2017).

18. Park, Y.-U. et al. Tailoring a fluorophosphate as a novel $4 \mathrm{~V}$ cathode for lithium-ion batteries. Scientific Reports 2, 704 (2012).

19. Ortiz, G. F. et al. Enhancing the energy density of safer Li-ion batteries by combining high-voltage lithium cobalt fluorophosphate cathodes and nanostructured titania anodes. Scientific Reports 6, 20656 (2016).

20. Yang, H., Zhuang, G. V. \& Ross Jr, P. Thermal stability of LiPF $_{6}$ salt and Li-ion battery electrolytes containing LiPF 6 . J. of Power Sources 161, 573-579 (2006).

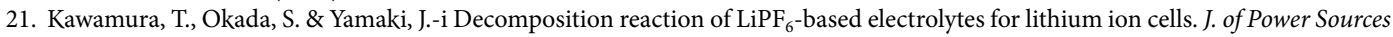
156, 547-554 (2006).

22. Documentation for immediately dangerous to life or health concentrations (IDLHs) for hydrogen fluoride (as F). The National Institute for Occupational Safety and Health (NOISH) (1994).

23. Acute exposure guideline levels for selected airborne chemicals: volume 4, subcommittee on acute exposure guideline levels. ISBN: 0-309-53013-X. Committee on Toxicology, National Research Council (2004).

24. Middelman, A. Hygiensiska gränsvärden AFS 2015:7, Hygieniska gränsvärden. Arbetsmiljöverkets föreskrifter om hygieniska gränsvärden och allmänna råd om tillämpningen av föreskrifterna. ISBN 978-91-7930-628-1. ISSN 1650-3163. Swedish Work Environment Authority (2015).

25. Guéguen, A. et al. Decomposition of $\mathrm{LiPF}_{6}$ in high energy lithium-ion batteries studied with online electrochemical mass spectrometry. J. of The Electrochem. Soc. 163(6), A1095-A1100 (2016). 
26. Chatelain, M. D. \& Adams, T. E. Lithium ion gas sampling of vented cells. Proceedings of the Power Sources Conference 42, 87-89 (2006).

27. Blum, A. F. \& Long Jr, R. T. Hazard assessment of lithium ion battery energy storage systems. Fire Protection Research Foundation (2016).

28. Larsson, F., Andersson, P., Blomqvist, P., Lorén, A. \& Mellander, B.-E. Characteristics of lithium-ion batteries during fire tests. J. of Power Sources 271, 414-420 (2014).

29. Larsson, F., Andersson, P., Blomqvist, P. \& Mellander, B.-E. Gas emissions from Lithium-ion battery cells undergoing abuse from external fire in Conference proceedings of Fires in vehicles (FIVE) 2016 (eds. Andersson, P. \& Sundstrom, B.) 253-256 (SP Technical Research Institute of Sweden, 2016).

30. Ribière, P. et al. Investigation on the fire-induced hazards of Li-ion battery cells by fire calorimetry. Energy Environ. Sci. 5, 5271-5280 (2012).

31. Lecocq, A. Scenario-based prediction of Li-ion batteries fire-induced toxicity. J. of Power Sources 316, 197-206 (2016).

32. Lecocq, A., Bertana, M., Truchot, B. \& Marlair, G. Comparison of the fire consequences of an electric vehicle and an internal combustion engine vehicle in Conference proceedings of Fires in vehicles (FIVE) 2012 (eds. Andersson, P. \& Sundstrom, B.) 183-193 (SP Technical Research Institute of Sweden, 2012).

33. Ohsaki, T. et al. Overcharge reaction of lithium-ion batteries. J. of Power Source 146, 97-100 (2005).

34. Abraham, D. P. et al. Diagnostic examination of thermally abused high-power lithium-ion cells. J. of Power Sources 161, 648-657 (2006).

35. Roth, E. P. Abuse response of $18650 \mathrm{Li}$-ion cells with different cathodes using EC:EMC/LiPF 6 and EC:PC:DMC/LiPF ${ }_{6}$ electrolytes. ECS Transactions 11(19), 19-41 (2008).

36. Golubkov, A. W. et al. Thermal-runaway experiments on consumer Li-ion batteries with metal-oxide and olivin-type cathodes. RSC Adv. 4, 3633-3642 (2014)

37. Golubkov, A. W. et al. Thermal runaway of commercial 18650 Li-ion batteries with LFP and NCA cathodes-impact of state of charge and overcharge. RSC Adv. 5, 57171-57186 (2015).

38. Spinner, N. S. et al. Physical and chemical analysis of lithium-ion battery cell-to-cell failure events inside custom fire chamber. J. of Power Sources 279, 713-721 (2015).

39. Fu, Y. et al. An experimental study on burning behaviors of 18650 lithium ion batteries using a cone calorimeter. J. of Power Sources 273, 216-222 (2015).

40. Huang, P., Wang, Q., Li, K., Ping, P. \& Sun, J. The combustion behavior of large scale lithium titanate battery. Scientific Reports 5, 7788 (2015).

41. Ping, P. et al. Study of the fire behavior of high-energy lithium-ion batteries with full-scale burning test. J. of Power Sources $\mathbf{2 8 5}$, $80-89(2015)$.

42. Roth, E. P. \& Orendorff, C. J. How electrolytes influence battery safety. The Electrochem. Soc. Interface, summer 2012, 45-49 (2012).

43. Eshetu, G. G. et al. In-depth safety-focused analysis of solvents used in electrolytes for large scale lithium ion batteries. Phys. Chem. Chem. Phys. 15, 9145-9155 (2013).

44. Lamb, J., Orendorff, C. J., Roth, E. P. \& Langendorf, J. Studies on the thermal breakdown of common Li-ion battery electrolyte components. J. of The Electrochem. Soc. 162(10), A2131-A2135 (2015).

45. Eshetu, G. G. et al. Fire behavior of carbonates-based electrolytes used in Li-ion rechargeable batteries with a focus on the role of the $\mathrm{LiPF}_{6}$ and LiFSI salts. J. of Power Sources 269, 804-811 (2014).

46. Andersson, P., Blomqvist, P., Lorén, A. \& Larsson, F. Using Fourier transform infrared spectroscopy to determine toxic gases in fires with lithium-ion batteries. Fire and Materials 40(8), 999-1015 (2016)

47. Lux, S. F. The mechanism of HF formation in $\mathrm{LiPF}_{6}$ based organic carbonate electrolytes. Electrochem. Comm. 14, 47-50 (2012).

48. Lux, S. F., Chevalier, J., Lucas, I. T. \& Kostecki, R. HF formation in LiPF ${ }_{6}$-based organic carbonate electrolytes. ECS Electrochem. Lett. 2(12), A121-A123 (2013)

49. Wilken, S., Treskow, M., Scheers, S., Johansson, P. \& Jacobsson, P. Initial stages of thermal decomposition of LiPF ${ }_{6}$-based lithium ion battery electrolytes by detailed Raman and NMR spectroscopy. RSC Adv. 3, 16359-16364 (2013).

50. Hammami, A., Raymond, N. \& Armand, M. Runaway risk of forming toxic compounds. Nat. 424, 635-636 (2013).

51. Campion, C. L. et al. Suppression of toxic compounds produced in the decomposition of lithium-ion battery electrolytes. Electrochem. and Solid-State Lett. 7(7), A194-A197 (2004).

52. Liu, X. et al. Heat release during thermally-induced failure of a lithium ion battery: impact of cathode composition. Fire Safety Journal 85, 10-22 (2016).

53. Lyon, R. E. \& Walters, R. N. Energetics of lithium ion battery failure. J. of hazardous materials 318, 164-172 (2016).

54. EN 13823:2010. Reaction to fire tests for building products-building products excluding floorings exposed to the thermal attack by a single burning item. European Committee for Standardization (2010).

55. EN 13501-1:2007 + A1:2009. Fire classification of construction products and building elements - part 1: classification using data from reaction to fire tests. European Committee for Standardization (2009).

56. ISO 19702:2006. Toxicity testing of fire effluents-guidance for analysis of gases and vapours in fire effluents using FTIR gas analysis. International Organization for Standardization (2006).

57. Andersson, P., Blomqvist, P., Lorén, A. \& Larsson, F. Investigation of fire emissions from Li-ion batteries. SP Technical Research Institute of Sweden. SP Report 2013:5 (2013).

58. Hollas, J. M. Modern Spectroscopy, 3ed. (John Wiley \& Sons, 1996).

\section{Acknowledgements}

The Swedish Energy Agency and its FFI-program, and Carl Tryggers Stiftelse för Vetenskaplig Forskning are acknowledged for their financial support. Several persons at RISE Research Institutes of Sweden and Chalmers University of Technology have been involved in this work and are gratefully acknowledged.

\section{Author Contributions}

F. Larsson planned the experiments, partially together with P. Andersson and B.-E. Mellander. P. Andersson made the initial data process of the SBI heat release data. P. Blomqvist planned and performed the FTIR and gas-washing bottles measurements and made the initial data processing. F. Larsson prepared the batteries and performed the measurement and data analyses of temperature, cell voltage and water mist, and did the postmeasurements and final data processing. Water mist setup was planned and constructed by B.-E. Mellander and F. Larsson. All four authors were involved in the analyses of the data and wrote the paper.

\section{Additional Information}

Competing Interests: The authors declare that they have no competing interests.

Publisher's note: Springer Nature remains neutral with regard to jurisdictional claims in published maps and institutional affiliations. 
(i) Open Access This article is licensed under a Creative Commons Attribution 4.0 International License, which permits use, sharing, adaptation, distribution and reproduction in any medium or format, as long as you give appropriate credit to the original author(s) and the source, provide a link to the Creative Commons license, and indicate if changes were made. The images or other third party material in this article are included in the article's Creative Commons license, unless indicated otherwise in a credit line to the material. If material is not included in the article's Creative Commons license and your intended use is not permitted by statutory regulation or exceeds the permitted use, you will need to obtain permission directly from the copyright holder. To view a copy of this license, visit http://creativecommons.org/licenses/by/4.0/.

(C) The Author(s) 2017 